\title{
Patency of the posterior communicating artery following treatment with the Pipeline Embolization Device
}

\author{
Badih Daou, MD, ${ }^{1}$ Edison P. Valle-Giler, MD, ${ }^{1}$ Nohra Chalouhi, MD, ${ }^{1}$ Robert M. Starke, MD, ${ }^{2}$ \\ Stavropoula Tjoumakaris, MD, ${ }^{1}$ David Hasan, MD, ${ }^{3}$ Robert H. Rosenwasser, MD, ${ }^{1}$ \\ Ryan Hebert, MD, ${ }^{1}$ and Pascal Jabbour, MD'1
}

\begin{abstract}
1Department of Neurological Surgery, Thomas Jefferson University and Jefferson Hospital for Neuroscience, Philadelphia, Pennsylvania; ${ }^{2}$ Department of Neurological Surgery, University of Virginia Health Sciences Center, Charlottesville, Virginia; and ${ }^{3}$ Department of Neurological Surgery, University of lowa, lowa City, lowa
\end{abstract}

\begin{abstract}
OBJECTIVE The Pipeline Embolization Device (PED) has become an effective treatment strategy for some cerebral aneurysms. Concerns regarding the patency of branch arteries have been raised. The objective of this study was to assess the patency of the posterior communicating artery (PCOA) following treatment of PCOA aneurysms using the PED.

METHODS All patients with PCOA aneurysms treated with the PED who had angiographic follow-up were retrospectively identified. The patency of the PCoA at follow-up was evaluated by 2 authors who were not involved in the intervention. Univariate and multivariate analyses were performed to identify factors associated with the following: 1) PCoA patency versus no or diminished flow, and 2) PCoA patency and diminished flow versus PCoA occlusion.
\end{abstract}

RESULTS Thirty patients with an angiographic follow-up of 6 months were included. Aneurysm obliteration was achieved in 25 patients $(83.3 \%)$. The PCoA was patent in 7 patients $(23.3 \%)$, had diminished flow in 7 patients $(23.3 \%)$, and was occluded in 16 patients (53.3\%). In the univariate analysis of outcome, there was a trend for aneurysms with incomplete occlusion, aneurysms not previously treated, those with presence of a fetal PCoA, and those with an artery coming from the aneurysm to have higher odds of the PCoA remaining patent. In univariate and multivariate analyses of factors associated with outcome, fetal PCoA and presence of an artery coming from the aneurysm were associated with the PCoA remaining open with or without diminished flow. No patients had symptoms related to PCoA occlusion.

CONCLUSIONS Occlusion and diminished flow through the PCOA is common following PED treatment of PCOA aneurysms. However, it is clinically insignificant in most cases.

http://thejns.org/doi/abs/10.3171/2016.2.JNS152544

KEY WORDS flow diversion; patency; Pipeline Embolization Device; posterior communicating artery; vascular disorders

$\mathrm{W}$ ITH the advancements in endovascular techniques, an increasing number of cerebral aneurysms are being managed using this approach. Flow diversion using the Pipeline Embolization Device (PED) has become a popular method for the management of cerebral aneurysms. In 2011, the PED (Covidien) was approved by the US FDA for the treatment of large and giant wide-neck aneurysms in the internal carotid artery (ICA), from the petrous to the superior hypophyseal segments. Since then, several reports have highlighted the safety and efficacy of the PED in the management of intracranial aneurysms. ${ }^{1,5,9,16}$ This device has also been used to treat other types of aneurysms, especially more distal anterior circulation aneurysms. ${ }^{7}$ The PED acts as a scaffold for endothelial overgrowth, disrupting flow across the aneurysm neck and inducing thrombosis of the aneurysm sac. ${ }^{13}$ An important concern that was raised with the use of the PED was the potential to cause occlusion of arterial side branches covered by the device as a result of parent vessel remodeling that occurs through neointimal endo-

ABBREVIATIONS ICA = internal carotid artery; MRA = MR angiography; PCoA = posterior communicating artery; PED = Pipeline Embolization Device; PRU = P2Y12 reaction units; $\mathrm{SAH}=$ subarachnoid hemorrhage. SUBMITTED November 2, 2015. ACCEPTED February 11, 2016.

INCLUDE WHEN CITING Published online May 6, 2016; DOI: 10.3171/2016.2.JNS152544. 
thelial proliferation. ${ }^{22}$ The objective of this study was to assess the patency of the posterior communicating artery (PCoA) following treatment of PCoA aneurysms using the PED.

\section{Methods \\ Patient Selection}

The study protocol was approved by the Thomas Jefferson University institutional review board. Patients who had PCoA aneurysms treated with the PED between May 2011 and July 2014 were retrospectively identified from our prospectively maintained database of patients undergoing treatment using the PED. Thirty-six patients with PCoA aneurysms were identified, of whom 6 were excluded because of loss to follow-up. Electronic medical records were reviewed for the 30 patients included in this study to identify patient demographic data, aneurysm characteristics, and the occurrence of any postoperative complications and symptoms related to the procedure. The angiograms were evaluated by 2 independent authors who were not involved in the procedure to confirm the coverage of the PCoA by the PED and to assess angiographic outcomes including patency of the PCoA and aneurysm occlusion. The flow through the PCoA was classified into the following 3 categories: patent, diminished, or occluded. All patients underwent a 4-vessel cerebral angiogram prior to initial placement of the PED, followed by a 1-vessel angiogram and MR angiography (MRA) on 6-month follow-up. Occlusion of the PCoA versus diminished flow was determined based on follow-up angiography (anterior circulation injections only) and MRA. The PCoA was considered occluded when there was no flow on follow-up angiography and no signal present on MRA.

Aneurysm occlusion was categorized into complete obliteration, near-complete obliteration ( $\geq 90 \%$ ), and incomplete occlusion $(<90 \%)$. All patients were placed on a dual antiplatelet therapy consisting of $81 \mathrm{mg} /$ day of aspirin and $75 \mathrm{mg} /$ day of clopidogrel at least 10 days prior to the intervention and were maintained on antiplatelet treatment for at least 6 months following treatment. The P2Y12 assay was used preoperatively to assess platelet response to clopidogrel.

\section{Statistical Analysis}

Data are presented as the mean and range for continuous variables and as the frequency for categorical variables. Statistical analyses of categorical variables were performed using the chi-square and Fisher's exact tests, and comparison of means was done using the Wilcoxon rank-sum test as appropriate. Univariate analysis was used to test covariates predictive of the following dependent variables: 1) PCoA patency versus no or diminished flow following treatment with the PED, and 2) PCoA patency and diminished flow versus PCoA occlusion. The following factors were assessed for their ability to predict PCoA patency: patient age, sex, hypertension, smoking, aneurysm size, aneurysm form, previous aneurysm treatment, aneurysm occlusion status, number of PEDs used, presence of a fetal PCoA variant, and if the artery was coming from the aneurysm on angiographic evaluation. Factors that were predictive in univariate analysis $(\mathrm{p}<0.20)$ were entered into a multivariate logistic regression analysis. A $p$ value $\leq 0.05$ was considered statistically significant. Statistical analysis was performed using Stata version 10.0 (StataCorp).

\section{Results}

\section{Baseline Characteristics}

Thirty patients with aneurysms arising from the PCoA were included in the study. The angiographic/MRA follow-up for all patients was 6 months; after that, patients were followed with yearly MRA. The mean patient age was $54 \pm 11.6$ years. Twenty-four patients were women $(80 \%)$ and 6 were men (20\%). Seventeen patients had a history of hypertension (56.7\%). Eighteen patients had a history of tobacco smoking (60\%). The mean aneurysm size was $7.2 \pm 3.6 \mathrm{~mm}$. Twenty-six aneurysms were saccular (86.7\%), and 4 were fusiform (13.3\%). Fifteen aneurysms were previously treated with coil embolization and recurred (50\%), and 15 aneurysms were managed with the PED as a first-line treatment (50\%). None of the patients in our study presented with subarachnoid hemorrhage (SAH) at the time of PED placement, but 11 of the patients with prior treatment had presented with SAH initially at the time of the first coiling intervention. The PCoA was covered by 1 PED in 27 patients (90\%) and by 2 devices in 3 patients $(10 \%)$. The mean number of PEDs that were placed was $1.1 \pm 0.3$. Six patients had a fetal PCoA variant (20\%). On angiography, 12 patients had an arterial branch coming from the aneurysm (40\%). The mean preoperative P2Y12 reaction unit (PRU) value was 140 (Table 1).

TABLE 1. Baseline demographic data for 30 patients and aneurysm characteristics

\begin{tabular}{lc}
\hline \multicolumn{1}{c}{ Variable } & Value* \\
\hline Mean age in yrs \pm SD & $54 \pm 11.6$ \\
\hline Sex & $6(20)$ \\
\hline M & $24(80)$ \\
\hline Hypertension & $17(56.7)$ \\
\hline Smoking & $18(60)$ \\
\hline Mean aneurysm size in mm \pm SD & $7.2 \pm 3.6$ \\
\hline Aneurysm type & \\
\hline Saccular & $26(86.7)$ \\
\hline Fusiform & $4(13.3)$ \\
\hline Previously treated aneurysm & $15(50)$ \\
\hline$>1$ PED used & $3(10)$ \\
\hline Fetal PCoA & $6(20)$ \\
\hline Artery coming from aneurysm & $12(40)$ \\
\hline Average preop PRU & 140 \\
\hline Aneurysm treatment status & \\
\hline Complete occlusion & $25(83.3)$ \\
\hline Near-complete occlusion & $1(3.3)$ \\
\hline Incomplete occlusion & $4(13.3)$ \\
\hline
\end{tabular}

$\mathrm{PRU}=\mathrm{P} 2 \mathrm{Y} 12$ reaction units.

* Values are expressed as the no. (\%) unless otherwise indicated. 


\section{Efficacy and Safety of the PED in Treating PCoA Aneurysms}

Complete aneurysm occlusion was achieved in 25 patients $(83.3 \%)$. As evaluated on the latest follow-up angiogram, 1 patient had near-complete ( $>90 \%$ obliteration) occlusion of his aneurysm (3.3\%), and 4 aneurysms were incompletely occluded (13.3\%). None of the patients had any hemorrhagic or thromboembolic complications. One patient developed an infected femoral pseudoaneurysm that resulted from arterial access and that required surgical management with proximal external iliac to distal common femoral artery bypass. There were no deaths. Instent stenosis was observed in 2 patients $(6.7 \%)$, both < $50 \%$ stenosis. Four of 6 aneurysms $(66.7 \%)$ originating on a fetal PCoA were completely occluded following treatment with the PED versus 21 of 24 aneurysms (87.5\%) originating on a nonfetal PCoA $(\mathrm{p}=0.3)$.

\section{Patency of the PCoA}

After placement of the PED, the PCoA was patent in 7 patients (23.3\%), patent with diminished flow in 7 patients (23.3\%), and occluded in 16 patients (53.3\%) at 6-month angiographic and MRA follow-up. The mean age was 54.7 \pm 11.3 years in patients with diminished or no flow in the PCoA versus $52.6 \pm 13.2$ years in patients with preserved flow. The mean aneurysm size was $6.6 \pm 4 \mathrm{~mm}$ in those with diminished or no flow in the PCoA versus $8.9 \pm 1.7$ $\mathrm{mm}$ in those with preserved flow. There were 13 of 23 previously treated aneurysms $(56.5 \%)$ in patients with decreased or no flow in the PCoA versus 2 of 7 previously treated aneurysms $(28.6 \%)$ in patients with patent PCoA.

The rate of PCoA occlusion was 51.8\% (14 of 27) when covered by 1 device versus $66.7 \%$ ( 2 of 3 ) when covered by 2 devices. Complete and near-complete aneurysm occlusion was achieved in 5 of 7 patients (71.4\%) with patent PCoA versus 22 of $23(95.6 \%)$ in patients with decreased or no flow. In patients with a patent PCoA, there were 3 of 7 fetal PCoAs (42.9\%) versus 3 of 23 in patients with an occluded PCoA or diminished flow (13\%). Furthermore, none of the fetal PCoAs were completely occluded; 3 were completely patent and 3 had decreased flow.

Five patients with a patent PCoA had the artery emanating from the aneurysm (71.4\%) versus 7 patients with an occluded PCoA or diminished flow (30.4\%). None of the patients who had diminished or no flow within the PCoA developed clinical symptoms. Five patients had a 1-year follow-up angiogram (3 PCoAs with no flow and 2 patent arteries) with no change in the PCoA occlusion status from the 6-month follow-up angiogram.

Univariate analysis of factors associated with PCoA patency versus no or diminished flow did not reveal any statistically significant associations, although aneurysms with incomplete occlusion (OR 8.85, 95\% CI 0.7-111.6; p $=0.09$ ), aneurysms not previously treated versus prior aneurysm treatment (OR 4.37, 95\% CI 0.68-27.98; $\mathrm{p}=0.1)$, presence of a fetal PCoA (OR 5, 95\% CI 0.73-34.34; $\mathrm{p}=$ 0.1 , and presence of an artery coming from the aneurysm (OR 5.71, 95\% CI 0.88-36.88; $\mathrm{p}=0.067$ ) showed a trend toward higher odds of the PCoA remaining patent after PED placement $(\mathrm{p} \leq 0.1)$. Multivariate analysis demonstrated that aneurysms with a PCoA projecting from the aneurysm had significantly higher odds of arterial patency after treatment with the PED (OR 8.57, 95\% CI 1.0569.38; $\mathrm{p}=0.04$ ), and there was a trend toward higher odds of the PCoA remaining patent in aneurysms that were not previously treated (OR 5.89, 95\% CI $0.71-48.72 ; \mathrm{p}=0.1$ ) (Table 2).

In univariate analysis of factors associated with the combined outcome of PCoA patency and diminished flow versus PCoA occlusion, the presence of a fetal PCoA (outcome predicted perfectly because none of the fetal PCoAs were completely occluded; $p=0.005)$, and the presence of an artery coming from the aneurysm (OR 17.5, 95\% CI 2.67-114.83; $p=0.003$ ) were the only factors significantly associated with the PCoA remaining open with or without diminished flow. Similarly, in multivariate analysis, the presence of a fetal PCoA (outcome predicted perfectly; $\mathrm{p}$ $=0.005)$ and the presence of an artery coming from the

TABLE 2. Univariate and multivariate analyses of PCOA patency versus no or diminished flow following treatment with the PED

\begin{tabular}{|c|c|c|c|c|c|c|}
\hline \multirow[b]{2}{*}{ Variable } & \multicolumn{3}{|c|}{ Univariate Analysis } & \multicolumn{3}{|c|}{ Multivariate Analysis } \\
\hline & OR & $95 \% \mathrm{Cl}$ & $p$ Value & OR & $95 \% \mathrm{Cl}$ & $\mathrm{p}$ Value \\
\hline Age & 0.98 & $0.90-1.06$ & 0.67 & - & - & - \\
\hline Sex & 1.90 & $0.26-13.52$ & 0.52 & - & - & - \\
\hline Smoking & 0.85 & $0.15-4.76$ & 0.86 & - & - & - \\
\hline Aneurysm size & 1.18 & $0.91-1.53$ & 0.19 & 1.34 & $0.75-2.37$ & 0.31 \\
\hline Aneurysm form & 1.11 & $0.96-12.74$ & 0.93 & - & - & - \\
\hline Previous SAH & 0.62 & $0.09-3.92$ & 0.61 & - & - & - \\
\hline Incomplete aneurysm occlusion & 8.85 & $0.7-111.6$ & 0.09 & 7.20 & $0.47-109.81$ & 0.15 \\
\hline Aneurysms not previously treated & 4.37 & $0.68-27.98$ & 0.1 & 5.89 & $0.71-48.72$ & 0.1 \\
\hline No. of PEDs & 1.75 & $0.13-22.77$ & 0.66 & - & - & - \\
\hline Fetal PCoA & 5.00 & $0.73-34.34$ & 0.1 & 1.88 & $0.02-126.86$ & 0.76 \\
\hline Artery coming from aneurysm & 5.71 & $0.88-36.88$ & 0.067 & 8.57 & $1.05-69.38$ & 0.04 \\
\hline PRU >200 & 1.26 & $0.11-13.59$ & 0.84 & - & - & - \\
\hline$P R U<60$ & - & - & 0.54 & - & - & - \\
\hline
\end{tabular}


aneurysm (OR 11.67, 95\% CI 1.49-91.54; $\mathrm{p}=0.019)$ significantly predicted the PCoA remaining patent with or without diminished flow (Table 3).

\section{Discussion}

To our knowledge, this is the largest study to assess PCoA patency following PED placement as well as the efficacy and safety of this device in the management of PCoA aneurysms. We also believe that this is the first study to present an analysis of factors specifically associated with the patency and occlusion of the PCoA. A high rate of aneurysm occlusion (a 90\% rate of complete and near-complete occlusion), combined with a low complication rate (1 groin complication with a $0 \%$ rate of hemorrhagic or thromboembolic complications), was observed with PED treatment of PCoA aneurysms. Although the rate of PCOA patency after placement of the PED was low (a 23.3\% patency rate and $23.3 \%$ of PCoAs with decreased flow), none of the patients developed any clinically related neurological symptoms that could compromise the safety of the intervention.

The PED has been most commonly used for the management of large, complex aneurysms of the ICA, with high efficacy and a low complication rate. ${ }^{1}$ In the Pipeline for Uncoilable or Failed Aneurysms trial, the rate of complete aneurysm occlusion was $86.8 \%$, with a rate of major ipsilateral stroke or neurological death of 5.6\%. ${ }^{1}$ A metaanalysis of 1451 patients with 1654 aneurysms treated with the PED showed a complete occlusion rate of $76 \%$ with a morbidity rate of $5 \%$, an intracerebral hemorrhage (ICH) rate of $3 \%$, and an ischemic stroke rate of $6 \% . .^{5}$ In a study by Chalouhi et al. that directly compared treatment using the PED with coiling, the complication rate was similar between the 2 groups (7.5\%), with attainment of complete aneurysm occlusion being significantly higher with PED treatment $(86 \%$ vs $41 \%){ }^{9}$

Given the promising results observed with this device, its use has been extended for the management of smaller, less complex aneurysms, especially in the anterior circulation. ${ }^{7}$ Kallmes et al. studied 793 patients with 906 aneurysms treated with the PED and found that the neurological morbidity and mortality rate was $8.4 \%$, with an ICH rate of $2.4 \%$ and an ischemic stroke rate of $4.7 \% .^{14}$ The best safety profile was achieved in anterior circulation aneurysms, mainly small ICA aneurysms. In this study, the PED is further shown to be a safe and effective tool in the management of PCoA aneurysms.

The occlusion rate of the PCoA was remarkably high following placement of the PED (53.3\%), with an additional 23.3\% of PCoAs having diminished flow on followup angiographic evaluation. Data regarding the patency of the PCoA following placement of the PED and its clinical significance are still scarce, with few studies in the literature addressing the subject., ${ }^{4,19,21,23} \mathrm{Yu}$ et al. reported that occlusion of covered arterial side branches 6 months after treatment with the PED occurred in 2 of 140 patients (1.4\%), with both occluded branches occurring in PCoAs with no clinical consequence. ${ }^{23}$ Similarly, Saatci et al. reported that, in a study which included 251 aneurysms, arterial patency was compromised in 5 patients; all of these cases involved the PCoA during management of 5 PCoA aneurysms. ${ }^{19}$

Brinjikji et al. evaluated PCoA patency in 11 patients with 13 aneurysms who had a PED placed across the ostium of the PCoA. They reported that $27 \%$ of PCoAs were occluded and that $18 \%$ had diminished flow, with no patients having any resultant neurological deficits at followup after a mean follow-up of 12.6 months. ${ }^{4}$ In another study by Vedantam et al., which included 14 PCoAs with 1 or more PEDs placed across the ostium, only 1 PCoA was occluded (7.1\%) versus 13 PCoAs that remained patent $(92.8 \%)$ after a mean follow-up of 12.8 months. ${ }^{21}$ Similarly, no patients developed any clinical symptoms related to PCoA occlusion.

Our results show that the rate of PCoA occlusion fol-

TABLE 3. Univariate and multivariate analyses of PCOA patency and diminished flow versus PCoA occlusion following treatment with the PED

\begin{tabular}{|c|c|c|c|c|c|c|}
\hline \multirow[b]{2}{*}{ Variable } & \multicolumn{3}{|c|}{ Univariate Analysis } & \multicolumn{3}{|c|}{ Multivariate Analysis } \\
\hline & OR & $95 \% \mathrm{Cl}$ & $p$ Value & OR & $95 \% \mathrm{Cl}$ & $\mathrm{p}$ Value \\
\hline Age & 0.99 & $0.93-1.06$ & 0.91 & - & - & - \\
\hline Sex & 0.35 & $0.05-2.34$ & 0.28 & - & - & - \\
\hline Smoking & 0.71 & $0.16-3.11$ & 0.65 & - & - & - \\
\hline Hypertension & 0.96 & $0.22-4.10$ & 0.96 & - & - & - \\
\hline Aneurysm size & 0.89 & $0.70-1.12$ & 0.34 & - & - & - \\
\hline Aneurysm form & 3 & $0.27-32.74$ & 0.36 & - & - & - \\
\hline Previous SAH & 0.60 & $0.13-2.70$ & 0.51 & - & - & - \\
\hline Incomplete aneurysm occlusion & 3.36 & $0.33-33.95$ & 0.30 & - & - & - \\
\hline Previously treated aneurysm & 1.5 & $0.34-6.53$ & 0.58 & - & - & - \\
\hline No. of PEDs & 1.85 & $0.14-22.99$ & 0.63 & - & - & - \\
\hline Fetal PCoA & - & - & 0.005 & - & - & 0.005 \\
\hline Artery coming from aneurysm & 17.5 & $2.67-114.83$ & 0.003 & 11.67 & $1.49-91.54$ & 0.019 \\
\hline $\mathrm{PRU}>200$ & 1.38 & $0.19-9.76$ & 0.74 & - & - & - \\
\hline $\mathrm{PRU}<60$ & 10.4 & $0.51-213.53$ & 0.13 & - & - & - \\
\hline
\end{tabular}


lowing management with the PED is higher than previously reported, but this phenomenon is nevertheless a benign process. Occlusion of the PCoA occurs gradually over a period of 3-6 months following placement of the PED. This allows vessel occlusion to be clinically tolerated without any symptoms because of either immediate collateral supply or the development of collateral supply.

Arterial patency following PED treatment has been evaluated with other perforating and side branches, especially the ophthalmic artery, with higher reported patency rates. In a study of 19 patients with the PED placed across the ostium of the ophthalmic artery, Puffer et al. reported that the ophthalmic artery was occluded in $21 \%$ of patients, had slow antegrade flow in $11 \%$, and remained patent in $68 \%$ of patients after PED treatment; none of the patients had any visual or neurological symptoms. ${ }^{17}$ In another study by Szikora et al., 2 of 17 ophthalmic arteries were occluded (11.8\%) at the 6-month follow-up with no resulting symptoms..$^{20}$

Chalouhi et al. studied 95 patients who had 1 or more PEDs placed across the ophthalmic artery. They reported that arterial occlusion occurred in $7 \%$ of patients, decreased flow occurred in 4\%, whereas arterial patency was maintained in $89 \%$ of patients. ${ }^{6}$ Occlusion was symptomatic in 1 patient only. Larger vessels such as the PCoA and the ophthalmic artery usually have well-developed distal collaterals. This makes them more prone to occlusion following placement of the PED because the pressure gradient across the device is not sufficient to maintain flow within the artery due to the opposing effect of the distal collateral flow., 4

On the other hand, smaller vessels such as the anterior choroidal and lenticulostriate arteries and perforating vessels with no distal collaterals may maintain flow due to a pressure gradient across the ostium and are more likely to remain patent. $3,18,21$ The higher rate of ophthalmic artery patency after flow diversion can probably be attributed to a higher continued physiological demand with the ophthalmic than the PCoA. ${ }^{6}$ Furthermore, because both systems have an adequate collateral circulation, clinical symptoms do not usually develop in occluded arteries and in arteries with diminished flow.

A fetal PCoA variant is defined as a PCoA that has the same caliber as the $\mathrm{P}_{2}$ segment of the posterior cerebral artery and is associated with an atrophic $\mathrm{P}_{1}$ segment. ${ }^{11}$ Its incidence is estimated to be between $4 \%$ and $29 \%$ of patients (20\% in the current study), with bilateral fetal PCoA variants occurring in $1 \%-9 \%$ of patients. ${ }^{2,12}$ Furthermore, approximately $10 \%$ of all PCoA aneurysms are associated with a fetal variant. ${ }^{15,24}$ Because fetal PCoAs represent the only supply to the posterior cerebral artery, care should be taken when treating PCoA aneurysms incorporating a fetal variant. ${ }^{11}$ In fact, fetal PCoA aneurysms are often treated surgically because endovascular therapy is thought to pose a higher treatment risk. A fetal PCoA is an end vessel with no distal collaterals. ${ }^{15}$ Compromise to the flow may result in infarction and significant neurological symptoms. This is in contrast to nonfetal PCoAs, where occlusion is usually asymptomatic due to well-developed distal collaterals..$^{15}$ Our results show that fetal PCoAs are less likely to be occluded following placement of the PED. None of the fetal PCoA variants were completely occluded versus 16 of $24(66.7 \%)$ of the nonfetal PCoAs. This is thought to be due to the high flow through fetal PCoAs and the high physiological demand for this artery, which maintains pressure gradient across the ostium. Furthermore, there was a nonsignificant trend in which aneurysms arising from a fetal PCoA had a lower occlusion rate. It seems that not only are fetal PCoAs more likely to remain patent after PED treatment, but the aneurysms arising from the fetal variant also tend to persist more often.

Patency of the PCoA was more likely to be preserved in aneurysms that were incompletely occluded with the PED (the association approached significance). Flow diverters work by inducing endoluminal vessel reconstruction to cause aneurysm occlusion. ${ }^{13}$ The same neointimal response may lead to branch vessel occlusion. As such, when this endothelial process has not occurred to its fullest extent (resulting in an incompletely occluded aneurysm), arterial patency is more likely to be preserved.

Another association that approached significance was that PCoA patency was more likely to be maintained in PCoA aneurysms that were not previously coiled. Because the PED is often used to treat previously coiled aneurysms ${ }^{10}$ it should be kept in mind that prior endovascular interventions in addition to placement of the PED can increase the risk of flow reduction. Additionally, PCoA occlusion was more common when the artery was covered by 2 devices $(66.7 \%)$ compared with $1(51.8 \%)$. However, because only 3 patients had placement of 2 PEDs, the association was not significant. The use of a single PED for treatment of intracranial aneurysms should be highly encouraged because a single device is usually enough for occlusion of most aneurysms, and additional devices may increase the morbidity, cost, and radiation exposure. ${ }^{8}$

This study is limited by its nonrandomized, retrospective, single-center design as well as a short follow-up period. Because most identified patients had an angiogram performed at 6 months, we chose 6 months as the study end point. However, all patients who had later angiographic evaluation had the same PCoA patency status as that obtained at 6 months. During the study period, PCoA aneurysms were also treated with other endovascular and surgical approaches depending on the treating neurosurgeon's assessment. This could have introduced selection bias for patients who were thought to be symptomatic from PCoA occlusion. This study addresses the patency of the PCoA and is not necessarily generalizable to other perforators and side branches covered by the PED. However, it provides valuable data pertaining to the patency of the PCoA after PED treatment.

\section{Conclusions}

Occlusion and diminished flow through the PCoA are common following PED treatment of PCoA aneurysms. However, they are not clinically significant in most cases. This is accompanied by a high success rate of the PED in treating PCoA aneurysms and a low complication rate. Patency of the PCoA is more likely to be preserved in fetal PCoA variants and in cases in which the artery is coming from the aneurysm. In this latter group, both the artery 
and the aneurysm are more likely to persist after treatment with the PED. Other important factors that may reduce the patency of the PCoA include prior coiling of the PCOA aneurysm and placement of more than 1 device across the PCoA. Larger studies with a prospective design are required to further evaluate the patency of side branches following treatment with the PED.

\section{References}

1. Becske T, Kallmes DF, Saatci I, McDougall CG, Szikora I, Lanzino G, et al: Pipeline for uncoilable or failed aneurysms: results from a multicenter clinical trial. Radiology 267:858868,2013

2. Bisaria KK: Anomalies of the posterior communicating artery and their potential clinical significance. J Neurosurg 60:572-576, 1984

3. Brinjikji W, Kallmes DF, Cloft HJ, Lanzino G: Patency of the anterior choroidal artery after flow-diversion treatment of internal carotid artery aneurysms. AJNR Am J Neuroradiol 36:537-541, 2015

4. Brinjikji W, Lanzino G, Cloft HJ, Kallmes DF: Patency of the posterior communicating artery after flow diversion treatment of internal carotid artery aneurysms. Clin Neurol Neurosurg 120:84-88, 2014

5. Brinjikji W, Murad MH, Lanzino G, Cloft HJ, Kallmes DF: Endovascular treatment of intracranial aneurysms with flow diverters: a meta-analysis. Stroke 44:442-447, 2013

6. Chalouhi N, Daou B, Kung D, Zanaty M, Phillips JL, Tjoumakaris S, et al: Fate of the ophthalmic artery after treatment with the Pipeline embolization device. Neurosurgery 77:581-584, 2015

7. Chalouhi N, Starke RM, Yang S, Bovenzi CD, Tjoumakaris $S$, Hasan D, et al: Extending the indications of flow diversion to small, unruptured, saccular aneurysms of the anterior circulation. Stroke 45:54-58, 2014

8. Chalouhi N, Tjoumakaris S, Phillips JL, Starke RM, Hasan $\mathrm{D}, \mathrm{Wu} \mathrm{C}$, et al: A single pipeline embolization device is sufficient for treatment of intracranial aneurysms. AJNR Am J Neuroradiol 35:1562-1566, 2014

9. Chalouhi N, Tjoumakaris S, Starke RM, Gonzalez LF, Randazzo C, Hasan D, et al: Comparison of flow diversion and coiling in large unruptured intracranial saccular aneurysms. Stroke 44:2150-2154, 2013

10. Daou B, Starke RM, Chalouhi N, Tjoumakaris S, Khoury J, Hasan D, et al: The use of the Pipeline embolization device in the management of recurrent previously coiled cerebral aneurysms. Neurosurgery 77:692-697, 697, 2015

11. Golshani K, Ferrell A, Zomorodi A, Smith TP, Britz GW: A review of the management of posterior communicating artery aneurysms in the modern era. Surg Neurol Int 1:88, 2010

12. Horikoshi T, Akiyama I, Yamagata Z, Sugita M, Nukui H: Magnetic resonance angiographic evidence of sex-linked variations in the circle of Willis and the occurrence of cerebral aneurysms. J Neurosurg 96:697-703, 2002

13. Kallmes DF, Ding YH, Dai D, Kadirvel R, Lewis DA, Cloft HJ: A new endoluminal, flow-disrupting device for treatment of saccular aneurysms. Stroke 38:2346-2352, 2007

14. Kallmes DF, Hanel R, Lopes D, Boccardi E, Bonafé A, Cekirge $S$, et al: International retrospective study of the Pipeline embolization device: a multicenter aneurysm treatment study. AJNR Am J Neuroradiol 36:108-115, 2015

15. Kan P, Duckworth E, Puri A, Velat G, Wakhloo A: Treatment failure of fetal posterior communicating artery aneurysms with the pipeline embolization device. J Neurointerv Surg [epub ahead of print], 2015

16. O'Kelly CJ, Spears J, Chow M, Wong J, Boulton M, Weill A, et al: Canadian experience with the pipeline embolization device for repair of unruptured intracranial aneurysms. AJNR Am J Neuroradiol 34:381-387, 2013

17. Puffer RC, Kallmes DF, Cloft HJ, Lanzino G: Patency of the ophthalmic artery after flow diversion treatment of paraclinoid aneurysms. J Neurosurg 116:892-896, 2012

18. Raz E, Shapiro M, Becske T, Zumofen DW, Tanweer O, Potts $\mathrm{MB}$, et al: Anterior choroidal artery patency and clinical follow-up after coverage with the pipeline embolization device. AJNR Am J Neuroradiol 36:937-942, 2015

19. Saatci I, Yavuz K, Ozer C, Geyik S, Cekirge HS: Treatment of intracranial aneurysms using the pipeline flow-diverter embolization device: a single-center experience with longterm follow-up results. AJNR Am J Neuroradiol 33:14361446, 2012

20. Szikora I, Berentei Z, Kulcsar Z, Marosfoi M, Vajda ZS, Lee $\mathrm{W}$, et al: Treatment of intracranial aneurysms by functional reconstruction of the parent artery: the Budapest experience with the pipeline embolization device. AJNR Am J Neuroradiol 31:1139-1147, 2010

21. Vedantam A, Rao VY, Shaltoni HM, Mawad ME: Incidence and clinical implications of carotid branch occlusion following treatment of internal carotid artery aneurysms with the pipeline embolization device. Neurosurgery 76:173-178, 2015

22. Wong GK, Kwan MC, Ng RY, Yu SC, Poon WS: Flow diverters for treatment of intracranial aneurysms: current status and ongoing clinical trials. J Clin Neurosci 18:737-740, 2011

23. Yu SC, Kwok CK, Cheng PW, Chan KY, Lau SS, Lui WM, et al: Intracranial aneurysms: midterm outcome of pipeline embolization device - a prospective study in 143 patients with 178 aneurysms. Radiology 265:893-901, 2012

24. Zada G, Breault J, Liu CY, Khalessi AA, Larsen DW, Teitelbaum GP, et al: Internal carotid artery aneurysms occurring at the origin of fetal variant posterior cerebral arteries: surgical and endovascular experience. Neurosurgery 63 (1 Suppl 1):ONS55-ONS62, 2008

\section{Disclosures}

Dr. Jabbour is a consultant for Covidien. Dr. Tjoumakaris is a consultant for Covidien and Stryker.

\section{Author Contributions}

Conception and design: Jabbour, Daou, Valle. Acquisition of data: Daou, Valle, Chalouhi, Hebert. Analysis and interpretation of data: Jabbour, Daou, Valle, Chalouhi, Starke. Drafting the article: Jabbour, Daou, Valle. Critically revising the article: Jabbour, Daou, Valle, Tjoumakaris, Hasan. Reviewed submitted version of manuscript: all authors. Approved the final version of the manuscript on behalf of all authors: Jabbour. Statistical analysis: Starke. Administrative/technical/material support: Rosenwasser. Study supervision: Jabbour, Tjoumakaris, Hasan, Rosenwasser.

\section{Correspondence}

Pascal Jabbour, Division of Neurovascular Surgery and Endovascular Neurosurgery, Department of Neurological Surgery, Thomas Jefferson University Hospital, 901 Walnut St., 3rd Fl., Philadelphia, PA 19107. email: pascal.jabbour@jefferson.edu. 